\title{
A Study on Vertebral Compression Fracture in Postmenopausal Women with Back Pain in Two Medical College Hospitals of Bangladesh
}

\author{
Khairul Anam ${ }^{1}$ \\ Sumia Ahmed Tazri² \\ Fairzu Faiza ${ }^{3}$ \\ A K M Maruf Raza ${ }^{*}$
}

\author{
'250 Bedded General Hospital \\ Siraigani, Bangladesh. \\ ${ }^{2}$ Department of Obstetrics and Gynaecology \\ North Bengal Medical College \\ Dhanbandi, Sirajgani, Bangladesh. \\ ${ }^{3}$ Jahurul Islam Medical College and Hospital \\ Kishoregoni, Bangladesh. \\ ${ }^{4}$ Department of Pathology \\ Jahurul Islam Medical College \\ Kishoregoni, Bangladesh.
}

\begin{abstract}
Background: To determine the prevalence and nature of the vertebral compression fracture in postmenopausal women suffering from back pain in the rural communities of Bangladesh.

Materials and methods: Cross sectional study was conducted for the period January to December 2018 which included all postmenopausal women aged 55 years and above presented with back pain in the Obstetrics and Gynaecology and Orthopedic outpatient Departments of Jahurul Islam Medical College and North Bengal Medical College Hospitals. Vertebral fractures were diagnosed by $X$-Ray scanning of the spine based on predefined criteria.

Results: Prevalence of vertebral compression fracture was $30.6 \%$. Most of the subjects were highly active, of poor nutritional status and undergraduate. Majority (35.7\%) of the patients belonged to 55-59 years group but prevalence was highest in $70-75$ years of age. Maximum patients (48.1\%) sustained fracture at only one vertebra. Highest number of fracture (61.1\%) was found in the dorsolumbar region. Most of the fracture (44.8\%) was of biconcave shape. Most of the wedge deformities were present from $12^{\text {th }}$ thoracic and above and majority of the biconcave deformities were from $11^{\text {th }}$ thoracic and below.

Conclusion: Although the prevalence was low in comparison to other studies, it showed a great burden on our social life. The most important step in treating vertebral compression fractures is prevention and treatment of osteoporosis.
\end{abstract}

Key words: Vertebral compression fracture; Postmenopausal women; Back pain.

\section{INTRODUCTION}

Vertebral fractures are common among people with osteoporosis and they are a serious health issue ${ }^{1}$. Many publications indicate that vertebral fractures are the most common forms of osteoporotic fractures ${ }^{2,3}$. In the year 2000, there were an estimated 1.4 million osteoporosis related vertebral fractures worldwide ${ }^{4}$. The combination of vertebral fractures and osteoporosis is associated with increased morbidity and mortality ${ }^{5}$.

Prevalence of osteoporotic vertebral fracture is $11.8 \%$ in women and $13.8 \%$ in men and the rate increases with age $e^{6,7}$. Studies have suggested that having 1 vertebral compression fracture increases the risk of future vertebral compression fracture ${ }^{8}$. Among those with fractures, only one fracture is the commonest type; two and more fractures are present in approximately $30 \%$ of the cases. Due to a transitional region, thoracolumbar spine (From $12^{\text {th }}$ thoracic to $2^{\text {nd }}$ lumbar) is most vulnerable to fracture ${ }^{6}$.

The most important risk factor for vertebral compression fracture is osteoporosis, but there are a number of others, both modifiable and non-modifiable ${ }^{9}$. Postmenopausal women have the greatest risk because of hormonal changes which disrupts the bone microarchitecture and alters the contents of non-collagenous proteins in the bone matrix ${ }^{10}$. This structural deterioration of the tissue leads to fragile bones which are prone to fractures ${ }^{11}$. 
Fractures occur in these patients during trivial events. It has been hypothesized that fractures in vertebral bodies occur because of an increased load on the spine caused by contraction of paraspinal muscles ${ }^{12}$. It has been suggested that approximately $30 \%$ of compression fractures in patients with severe osteoporosis occur while the patient is in the bed ${ }^{13}$. Patients with moderate osteoporosis can injure their spine by falling off a chair, tripping, or attempting to lift a heavy object. Vertebral compression fractures have an insidious onset and may produce only low grade back pain. Pain is the most common symptom after vertebral compression fracture. Over time, multiple fractures may lead to progressive loss of stature and continuous contraction of the paraspinal musculature to maintain posture. This combination results in muscle fatigue and pain that may continue even after the original compression fractures have healed ${ }^{14}$.

Vertebral compression fracture can be classified in three categories: wedge (50\%), biconcave (17\%) and crush (13\%). Complex fractures account for the remaining $20 \%$ of vertebral compression fractures ${ }^{15}$.

Arm span is commonly used as a surrogate for maximum adult height for individuals with spinal deformity, and the difference between arm span and height serves as a measure of height loss ${ }^{16}$.

\section{MATERIALS AND METHODS}

All postmenopausal women presented with back pain in the outpatient Departments were enrolled for the study from January to December 2018. Informed consent was taken from the patients and those willing to participate were interviewed using a pretested semi structured interview schedule. It included age, socioeconomic status, obstetric history, past history of fracture, presence of other medical problem. Age ascertainment was done by directly asking age in completed years, correlating with important events like age at marriage, age at first child birth, present age of the child etc. Age at menarche was recorded as told by the women or/and correlated with personal life event like age at marriage, interval between menarche and marriage and also the period between menarche and first child birth. Age at menopause was recorded as told by the patient and/or correlated with personal life events like birth of youngest child. Mode of menopause was recorded as natural or surgical. Antero posterior and lateral X-Ray views of the dorsolumbar spinal region were taken to detect fracture.

The question on physical activity had four alternatives which were sedentary, moderate, high and very high. Having few answers both in the "sedentary" and "very high physical activity level" groups, we categorized sedentary and moderate physical activity level as low, and high/very high level as high. Five levels of self-perceived health (Very good, good, neither nor, bad, very bad) were categorized into two, good (Very good and good) and poor (Neither nor, bad, very bad). Educational information was combined from five to three levels: primary school only (i.e up to grade V level) up to SSC level and more than SSC level.

\section{Inclusion criteria}

i) Postmenopausal women

ii) Aged 55 years and above

iii) Suffering from back pain.

\section{Exclusion criteria}

i) Active smokers or with a history of moderate to severe asthma

ii) COPD, pulmonary fibrosis, emphysema or other major lung disease

iii) Study participants could not have taken inhaler delivered medications within the past 3 months or have any severe or chronically disabling conditions other than osteoporosis, such as congestive heart failure

iv) Patients were not selected for this study based on their need for an inhaler.

\section{Related definitions}

Arm Span:

Arm span was measured to the nearest centimeter from the tips of the middle fingers of maximally outstretched hands, with the patient standing facing the wall.

\section{Height:}

According to a standardized protocol, patients were measured in bare feet, with their back against the wall mounted Harpenden Stadiometer, heels together, and head positioned in the Frankfort horizontal plane. The patient was asked to breathe in, and height was noted and recorded at peak inspiration ${ }^{16}$.

Arm span and height measurements were taken one time.

\section{Type of Fracture:}

Three types of fractures are identified: wedge, biconcave and crush. The wedge fractures are characterized by deformed structure of the anterior part of the vertebrae, the biconcave of the middle part, and crush fractures caused by compression of the total vertebrae ${ }^{15}$.

\section{Severity of Fracture:}

Using lateral radiographs of the thoracic and lumbar spines, each vertebra was scored quantitatively as $0,1,2$, or 3 . Grade 0 indicated an unfractured vertebra, grade 1 is mild compression (approximately 20\%-25\%), grade 2 is moderate compression (Approximately 25\%-40\%) and grade 3 is severe compression $(>40 \%)^{17}$.

\section{RESULTS}

Total study population was 1000 among which 306 patients suffered from vertebral fractures yielding the prevalence rate $30.6 \%$. 
Table I : Patient Characteristics (n-1000)

$\begin{array}{llrr}\text { Factor } & & \begin{array}{r}\text { No fracture } \\ \text { (Mean } \pm \text { SD) }\end{array} & \begin{array}{r}\text { Fracture } \\ \text { (Mean } \pm \text { SD) }\end{array} \\ \text { Age } & 61 \pm 8.2 & 59 \pm 7.5 \\ \text { Height } & 150 \pm 6 & 154 \pm 7.1 \\ \text { Weight } & & 45 \pm 6.3 & 47 \pm 7.1 \\ \text { BMI } & 21.2 \pm 2.1 & 22.1 \pm 2.5 \\ \text { Education } & \text { 1 (Primary) } & 231 & 117 \\ & \text { 2 (Up to HSC) } & 320 & 134 \\ & \text { 3 (More than HSC) } & 143 & 55 \\ \text { Activity } & \text { Highly active } & 407 & 229 \\ & \text { Low active } & 189 & 175 \\ \text { Health } & \text { Good } & 247 & 197 \\ & \text { Poor } & 325 & 231 \\ \text { Number of pregnancy } & 3 \pm 1 & 3 \pm 1.1 \\ \text { Age at menarche } & 12 \pm 1.5 & 12 \pm 2.7 \\ \text { Age at menopause } & 49 \pm 4 & 46 \pm 4.7 \\ \text { Reproductive years } & 44 \pm 5 & 43 \pm 4.7\end{array}$

Almost all the subjects were of same parameters with little variation but a few more subjects were in the highly active, poor nutritional status, undergraduate group.

Table II : Prevalence of vertebral fracture according to age $(\mathrm{n}=1000)$

\begin{tabular}{lrrrrrr}
\multicolumn{2}{l}{$\begin{array}{l}\text { Age group } \\
\text { (Years) }\end{array}$} & \multicolumn{2}{c}{ With fracture } & \multicolumn{2}{c}{ Without fracture } & \multicolumn{2}{c}{ Total } \\
& \multicolumn{1}{c}{ No. } & $\%$ & \multicolumn{1}{c}{ No. } & $\%$ & No. & $\%$ \\
\hline $55-59$ & 56 & 5.6 & 301 & 30.1 & 357 & 35.7 \\
$60-69$ & 148 & 14.8 & 95 & 9.5 & 243 & 24.3 \\
$70-74$ & 176 & 17.6 & 37 & 3.7 & 213 & 21.3 \\
$\geq 75$ & 165 & 16.5 & 22 & 2.2 & 187 & 18.7 \\
\hline
\end{tabular}

Table III : Distribution of number of deformities $(n=306)$

\begin{tabular}{lrr} 
Number of deformities & Number \% (N) & Percentage \\
At least 1 deformity & 147 & 48.1 \\
2 deformities & 94 & 30.7 \\
3 or more deformities & 65 & 21.2 \\
Total & 306 & \\
\hline
\end{tabular}

Maximum patients (48.1\%) sustained fracture at only one vertebra.

Table IV: Distribution of deformities in different regions of the spine $(\mathrm{n}=306)$

\begin{tabular}{lrc} 
Spinal region & Number & percentage \\
Dorsal (T5-T11) & 64 & 20.9 \\
Dorsolumbar (T12-L2) & 187 & 61.1 \\
Lumbar (L3-L5) & 37 & 12.1 \\
Skipped regions & & \\
(i.e Upper Dorsal+ Lower Lumbar) & 18 & 5.9 \\
\hline
\end{tabular}

Highest number of fracture $(61.1 \%)$ was found in the dorsolumbar region. $5.9 \%$ fracture was found in a skipped manner. A history of trauma in the past was found in most of the cases.

Table V : Type of deformity in patients $(\mathrm{n}=306)$

\begin{tabular}{lcc} 
Type of deformity & Number of patient & Percentage \\
Wedge & 127 & 41.5 \\
Biconcave & 137 & 44.8 \\
Crush & 29 & 9.5 \\
$\begin{array}{l}\text { Mixed (Had more than } \\
\text { one type of fracture) }\end{array}$ & 13 & 4.2 \\
\hline
\end{tabular}

We found most of the fractures (44.8\%) in biconcave shape. Most of the wedge deformities were present from $12^{\text {th }}$ thoracic and above, and most of the biconcave deformities were from 11 th thoracic and below.

\section{DISCUSSION}

Age of the patient was a significant predictor of vertebral deformities in women with a prevalence increasing from approximately $5.6 \%$ in the age group below 60 years to approximately $34.1 \%$ in the age group $70+$ in women. Same finding was observed by others ${ }^{6}$. However the prevalence rate may be an underestimate because we could not validate actual age of the patients in every case due to lacking of certifications. For women, it can even be regarded as rather low compared to other studies reported from Vietnam to be from $17.1 \%$ in the age group $50-59$ to $39.2 \%$ in the age group $70+$ (Overall prevalence $23 \%$ ) and in Spain from $7.2 \%$ in the age group 5559 and $46.3 \%$ in the age group $75+\left(\right.$ Overall 21.4\%) ${ }^{6,18,19}$. Women with vertebral fractures were older, shorter, weighted less, had lower educational level, and lower self-reported health compared to those without fractures. Prevalence of vertebral fracture showed an increasing trend with increasing age. This is because an accelerated bone loss which occurs after menopause makes the bone fragile ${ }^{6}$.

Interpretation of height loss would be more relevant if the previous heights of the patients were recorded. Dietary insufficiency leading to short stature and generalized disease in bone mineral density may make the bone soft. Decreased height may also be due to collapse of the vertebra leading to inevitable loss of height.

In women, half (44.8\%) of the deformities were wedges, more than one third $(41.5 \%)$ were biconcave, and $9.5 \%$ were crush. Most of the wedge fractures occurred in midthoracic and lower lumbar regions where anterior wedging affected in the midthoracic and posterior wedging in lower lumbar regions. Kyphotic shape of thoracic spine and lordotic shape of lower lumbar spine put an unequal stress over anterior and posterior part of the vertebra leading to wedging of osteoporotic fragile vertebra. Most of the biconcave fractures were located in upper lumbar (L1-L3) spine. Similar finding was observed by others as well ${ }^{6}$. 
As reported by others, we also found the prevalence of vertebral deformities to be highest in the mid thoracic region (5th-9th thoracic) and thoracolumbar transition. ${ }^{20}$ Wedge deformities were mostly found in the higher thoracic and the biconcave in the lower thoracic and lumbar region. As the age of the patient increased, so the number of fracture increased also. Majority of the patients had fracture at one vertebra level because $60 \%$ of our study population was below 70 years of age.

Difference in fracture mechanisms may possibly explain the discrepancy in prevalence, as non-vertebral fractures are connected to falls, whereas vertebral fractures are not ${ }^{9,21}$. It has been reported that a large amount of vertebral fractures are asymptomatic $^{22}$. Some studies report that only one in three vertebral fractures are diagnosed and as such argue that vertebral fractures are largely under diagnosed ${ }^{22-25}$.

\section{CONCLUSION}

Osteoporotic fracture is a public health problem in our country so in the developed countries. As life expectancy is on the rise, policy makers should deploy necessary planning to reduce the load of fragility fractures and thereby improving quality of life of the elderly.

\section{ACKNOWLEDGEMENT}

The authors thank to Prof. Dr. Monira Ahmed, Prof. Dr. Ismat Ara, Department of Obstetrics and Gynaecology, JIMCH for their support to make this study a successful one.

\section{DISCLOSURE}

All the authors declared no competing interest. 


\section{REFERENCES}

1. Compston J. Ostoeoporosis: Social and economic impact. Radiol Clin North Am. 2010; 48(3): 477-482.

2. Tsai KS, Twu SJ, Chieng PU, Yang RS, Lee TK. The geriatric study group ROC Prevalence of vertebral fractures in Chinese men and women in urban Taiwaese communities. Calcif Tissue Int. 1996; 59(4): 249-253.

3. Francis R, Aspray T, Hide G, Sutcliffe A, Wilkinson P. Progression of osteoporosis in patients with COPD: A 3-year follow up study. Osteoporosis International. 2008; 19(7): 895-903.

4. Johnell O, Kanis JA. An estimate of the worldwide prevalence and disability associated with osteoporotic fractures. Osteoporosis Int. 2006; 17(12): 1726-1733.

5. Silva DR, Coelho AC, Dumke A. Osteoporosis prevalence and associated factors in patients with COPD: A crosssectional study. Respiratory Care. 2011; 56(7): 961-968

6. Waterloo S, Ahmed LA, Center JR, Eisman JA. Prevalence of vertebral fractures in women and men in the population-based Tromsø Study. BMC Musculoskeletal Disorders. 2012; 13(3): 1471-2474.

7. Black DM, Cummings SR, Karpf DB. Randomized trial of effect of alendronate on risk of fracture in women with existing vertebral fractures. Lancet. 1996; 348(9041): 1535-1541.

8. Lindsay R, Silverman SL, Cooper C. Risk of new vertebral fracture in the year following a fracture. JAMA. 2001; 285(3): 404-415.

9. Cummings SR, Melton LJ. Epidemiology and outcomes of osteoporotic fractures. Lancet. 2002; 359(9319): 1761-1767.

10. Resch A, Schneider B, Bernecker P. Risk of vertebral fractures in men: relationship to mineral density of the vertebral body. AJR Am Roentgenol. 1995; 164(6): 1447-1450.

11. Alexandru D, So W. Evaluation and Management of Vertebral Compression Fractures. The Permanente Journal. 2012; 16(4): 46-51.

12. Kim DH, Vaccaro AR. Osteoporotic compression fractures of the spine; current options and considerations for treatment. The Spine Journal. 2006; 6(5): 479-487.

13. Garfin SR, Yuan HA, Reiley MA. New technologies in spine: kyphoplasty and vertebroplasty for the treatment of painful osteoporotic compression fractures. Spine. 2001; 26(14): 1511-1515.

14. Wu SS, Lachmann E. Current medical, rehabilitation, and surgical management of vertebral compression fractures. J Womens Health. 2003; 12(1): 17-26.

15. Black DM, Arden NK, Palermo L, Pearson J, Cummings SR. Prevalent vertebral deformities predict hip fractures and new vertebral deformities but not wrist fractures. Study of Osteoporotic Fractures Research Group. J Bone Miner Res. 1999; 14(5): 821-828.

16. Parker JM, Dillard TA, Phillips YY. Arm span-height relationships in patients referred for spirometry. Am J Respir Crit Care Med. 1996; 154(2): 533-536.

17. Krege JH, Kendler D, Krohn K, Genant H, Alam J. Relationship between vertebral fracture burden, height loss, and pulmonary function in postmenopausal women with osteoporosis. Journal of Clincial Densiometry: Assessment and management of musculoskeletal health. 2015; 18(4): 506-511.

18. Ho-Pham LT, Nguyen ND, Vu BQ, Pham HN, Nguyen TV. Prevalence and risk factors of radiographic vertebral fracture in postmenopausal Vietnamese women. Bone. 2009; 45(2): 213-217.

19. Sanfélix J, Reig MB, Sanfélix G, Peiró S, Graells FM, Vega M. The population-based prevalence of osteoporotic vertebral fracture and densitometric osteoporosis in postmenopausal women over 50 in Valencia, Spain (The FRAVO Study). Bone. 2010; 47(3): 610-616.

20. Ensrud KE, Schousboe JT. Vertebral Fractures. N Engl J Med. 2011; 364(17): 1634-42.

21. Tsai KS, Twu SJ, Chieng PU, Yang RS, Lee TK. The Geriatric Study Group ROC Prevalence of vertebral fractures in Chinese men and women in urban Taiwanese communities. Calcific Tissue Int. 1996; 59(4): 249-253.

22. Kim N, Rowe BH, Raymond G, Jen H, Colman I, Jackson SA et al. Underreporting of vertebral fractures on routine chest radiography. Am J Roentgenol. 2004; 182(2): 297-300.

23. Francis R, Aspray T, Hide G, Sutcliffe A, Wilkinson P. Back Pain in Osteoporotis Vertebral Fractures. Osteoporos Int. 2008; 19(7): 895-903.

24. Cooper C. Epidemiology and public health impact of osteoporosis. Baillieres Clin Rheumatol. 1993; 7(3): 459-477.

25. Roux C, Fechtenbaum J, Kolta S, Briot K, Girard M. Mild prevalent and incident vertebral fractures are risk factors for new fractures. Osteoporos Int. 2007; 18(12): 1617-1624. 